\title{
The Relationship Between Human Resource Strategies and Organizational Performance Based on The Balanced Scorecard in a Public hospital in Iran: A Cross-Sectional Study
}

\section{Ebrahim Nafari}

Islamic Azad University

Behrooz Rezaei ( $\sim$ beh.rezaei@gmail.com )

Islamic Azad University

\section{Research Article}

Keywords: Human Resources Strategies, Organizational Performance, Balanced Scorecard, Hospital, Hospital Staff.

Posted Date: August 20th, 2021

DOl: https://doi.org/10.21203/rs.3.rs-823985/v1

License: (c) (1) This work is licensed under a Creative Commons Attribution 4.0 International License. Read Full License

Version of Record: A version of this preprint was published at BMC Health Services Research on March 18th, 2022. See the published version at https://doi.org/10.1186/s12913-022-07767-z. 


\section{Title page}

1 Title: The Relationship between human resource strategies and organizational performance

r based on the balanced scorecard in a public hospital in Iran: a cross-sectional study

$r \quad$ Running title: Human Resource Strategies and Organizational Performance

$\varepsilon$ Authors:

1. Ebrahim Nafari, MS, Department of Health \& Health Services Management, Medical Faculty, Shahrekord Branch, Islamic Azad University, Shahrekord, Iran. Email: abrahim n@yahoo.com, Tel:09132352574

2. Behrooz Rezaei, Associate Professor, $\mathrm{PhD}$ in Health Services Management, Nursing \& Midwifery Faculty, Falavarjan Branch, Islamic Azad University, Isfahan, Iran. Email: beh.rezaei@gmail.com, Tel: 00989131251556 Fax: 00983137420146 (Corresponding Author)

Y

$\Lambda$

9 


\section{Abstract:}

Background: Today, due to complex environment and rapidly changing of health industry, hospitals need to optimize their organizational performance to achieve a competitive advantage. One of the important factors for achieving competitive advantage is the effective human resources management through application of appropriate human resource strategies. The aim of this study was to investigate the relationship between human resource strategies and organizational performance based on the balanced scorecard.

Methods: A cross-sectional study was conducted among clinical and administrative staff in a public hospital in Isfahan, Iran. All eligible staff entered the study $(n=200)$. Data were collected using self reported questionnaires during July 2018. The main questionnaire contained 32 items which investigated employees' perceptions on human resource strategies (including seven strategies) and organizational performance based on the balanced scorecard approach. In order to analyzing data, Pearson correlation coefficient and multivariate regression analysis were applied using SPSS/21 software $(\mathrm{P}<0.05)$.

Results: In this study, 154 questionnaires were completed and returned (return rate $=77 \%$ ). Human resource strategies and organizational performance were evaluated at a medium level. There was a significant positive relationship between human resource strategies and organizational performance ( $\mathrm{r}$ $=0.73, \mathrm{p}=0.001)$. Pearson correlation coefficient showed that human resource strategies had the highest relationship with organizational performance in the dimension of growth and learning $(\mathrm{r}=$ $0.669, \mathrm{p}=0.001)$ and the least relationship with the dimension of financial performance $(\mathrm{r}=0.455$, 0.001). $0=\mathrm{p}$ ). Regression analysis showed that all human resources strategies were effective on organizational performance $(\mathrm{R}=0.998, \mathrm{R} 2=0.997$, ADJ.R2=0.997). Staff training and development strategy $($ Beta $=0.265, p=0.000)$, personnel compensation $($ Beta $=0.212, p=0.000)$ and recruitment strategy $($ Beta $=0.208, \mathrm{~B}, \mathrm{P}=0.000$ ) had the greatest impact on organizational performance respectively. 
1 Conclusion: In order to improve hospital performance, it seems that the development of human

$r$ resource strategies (especially staff training and development, and compensation strategy) can be

r considered by hospital managers. The findings of this study can be considered for developing hospital

$\varepsilon \quad$ performance in similar context.

- Keywords: Human Resources Strategies, Organizational Performance, Balanced Scorecard, Hospital,

1 Hospital Staff.

\ Background:

$\wedge$ Nowadays, human resources are recognized as resources that can create a valuable competitive 9 advantage for organization [1]. Competitive advantage can be achieved through employees and 1. various human resources management activities [2]. On the other hand, in order to achieve a competitive advantage, organizations must use tools to attract, retain, and motivate their human resources, which are called Human Resources Strategies (HRS) [1,3]. Otherwise, they will lose the ability to adapt to today's complex environment and the ability to use human resources effectively [3]. In fact, success in human resource management requires the development and implementation of appropriate HRS [4].

Strategic human resources management is considered as a link between HRS and the business strategy of the organization [5]. The goal of strategic human resources management is how organizations can use their human resources to improve their competitive performance [6].

HRS is the decision-making model of human resource system policies in the field of business strategy and competitive contexts [5]. HRS refers to the overall understanding of the organization on how to manage different aspects of employees in order to simultaneously strengthen the competitiveness and well-being of employees. HRS is the common view of management and employees about the type of human resources policies that should be implemented in the organization [4]. In fact, HRS reflect what the organization intends to do about the various aspects of its human resources management policies and practices [7]. A successful HRS determines what factors affect the success of an organization [4]. 
Understanding the nature of HRS is impossible without considering intra-organizational policies and environmental / institutional forecasts. Continuous and inimitable development of human resources is a key factor in achieving sustainable competitive advantage for organizations. Strategic human resources management is a process through which organizations seek to link the human and social capital of their members with the strategic needs of the organization, while HRS is a roadmap to provide this link and emerging human resources that the organizational leaders use it [5].

On the other hand, human resources management decisions are likely to have a significant and unique impact on organizational performance (OP) [8]. In the context of applying HRS, organizations can achieve optimal OP by making appropriate use of opportunities and situations [5].

Evaluating the OP improves the quality of products and services and helps reduce costs [9]. Improving the OP requires having a suitable model for performance evaluation, and in the meantime, the balanced scorecard (BSC) can be used as a successful model to evaluate the performance of service organizations, especially hospitals [10].

In order to achieve a new performance evaluation system, BSC is a successful tool for implementing strategic plans of the organization [11]. BSC is a strategic management system that is able to disseminate the knowledge, skills and capabilities of employees in order to achieve the strategic goals of the organization. The philosophy of the BSC is to turn an organization's vision, mission, and strategy into tailored goals in four dimensions: finance, customers, the internal process, and learning and growth [12]. In fact, by applying this model in these dimensions, criteria are selected to measure OP [13]. BSC is a comprehensive approach that considers an OP metrics in terms of financial and non-financial $[14,15]$. However, after more than 20 years of research and application, this approach has emerged in some studies in health care organizations. Despite this emerging analytical tool, studies on BSC in public organizations especially hospitals are still limited [15].

Over the past two decades, the focus of research on HRS has been in three areas. The first area is related to the formulation and implementation of HSR in which not only how to formulate the most effective HSR, but also the organizational characteristics of adopting specific methods of HSR have 
been considered. In the second area, the content of HRS (including dimensions and variables), especially the policies and different methods of HRS have been considered. While in the third area, the most attention of researchers has been focused on the effects of HRS, especially on OP [5].

Since the 1990s, much research has examined the relationship between HRS and OP. Most of this research has relied on evidence from organizations in the private sector, while in most countries; the public sector is the largest provider of services. On the other hand, the performance of public sector employees plays a vital role in the health and well-being of the people. In many countries, government agencies are facing declining resources and increasing demand for accountability and improving service quality. All these issues have made the study on human resources and performance of public service organizations an important context of research [16].

Meanwhile, health care organizations, as an important part of service organizations, are changing and complicating faster than other organizations. Modern health care is changing and becoming more complex due to new patterns of disease, advanced technologies, unpredictable patient needs, and diverse manpower needs [17]. Since hospitals provide important and vital care services for the community, it is essential that the development of research in this area be considered by researchers.

Numerous studies have been conducted in industrial organizations, but related research in health care organizations is limited. Research conducted in health care institutions indicates that the successful implementation of HRS improves the OP [2,3,6,18-22]. In this regard, a study in 16 Jordanian public hospitals showed that strategic human resources management factors had a significant relationship with positive hospital performance [6]. Michael et al. (2006) conducted a study in 52 UK hospitals and found that HSR have a significant and real relationship with reducing patient mortality [21]. In addition, Vermeeren et al. (2016) conducted a study in 162 Dutch health care institutions and showed that human resources management activities and strategies are affected on improving financial, organizational and staff results [2].

One of the main goals of human resources management is to increase the performance and organizational productivity. However, issues such as large investments, the use of expensive medical 
technology, and the constant increasing of hospital costs have made it even more necessary to optimize the productivity of hospital human resources. Past research indicates that the successful implementation of HRS improves the hospital performance but the available information in this context does not seem to be sufficient. On the other hand, due to the rapid changes in health care industry and special complexities of hospital management in recent decades, more research is needed in this context. As far as the authors know, no study has been previously conducted to investigate the relationship between HRS and OP of a hospital based on the balanced scored card approach. Therefore, the present study was conducted to determine the relationship between HSR and OP based on the balanced scorecard in a public hospital in Isfahan province, Iran.

Methods

Study design, setting \& sample

A cross-sectional study was conducted in a public hospital in Isfahan, Iran during July 2018. All eligible staff entered the study. Data were collected using the two questionnaires. The statistical population consisted all clinical and administrative staff of the hospital $(\mathrm{N}=250)$. Staffs with fulltime employment, one year or higher of work experience, associate education level or higher, informed consent to participate in the study were included in the study ( $n=200)$. Incompletely completed questionnaires were excluded from the study. Considering the inclusion and exclusion criteria, the data collected from 154 participants were finally analyzed.

\section{Data collection tools}

The instrument of this study consisted of two Persian questionnaires which printed version of those was completed by the participants via self-report method. The first questionnaire was demographic questionnaire included personal information such as age, gender, level of education, work experience, and type of employment. The second questionnaire consisted of 32 items on a 5-point Likert scale from very low (score 1) to very high (score 5), which simultaneously assessed employees' views on HRS and OP. Items related to HRS taken from the Chang \& Huang HRS Questionnaire (2005) in seven areas include; performance management (4 items), staff training and development (8 items), 
staff compensation and reward (4 items), recruitment (4 items), equal opportunities (4 items), staff relations (4 items), and flexible work programs (4 items) [23]. Organizational performance items are also based on the balanced scorecard derived from the view of Kaplan \& Norton (1996) in four dimensions including; customer ( 8 items), financial ( 8 items), Internal process ( 8 items), and learning and growth (8 items)[13]. This questionnaire was designed by Ghasemi (2013) and its validity was confirmed by content validity method and its reliability was confirmed by Cronbach's alpha coefficient of 0.88 [9]. In the present study, the reliability of this instrument was confirmed by Cronbach's alpha coefficient of 0.94 .

\section{Data analysis}

Data were analyzed using descriptive statistics (including frequency distribution tables, mean and standard deviation) and analytical statistics (including Pearson correlation coefficient \& multivariate regression analysis) using SPSS /20 software at a significance level of 0.05 . The KolmogorovSmirnov test was used to evaluate the normality of the distribution of variables.

\section{Results:}

In present study, 154 questionnaires were completed and returned (return rate $=77 \%$ ). Descriptive results showed that the majority of participants (75.5\%) were women and half of them (49.4\%) were in the age group of 30 to 40 years. More than half of the participants (58.4\%) had a bachelor's degree. Also, $43.5 \%$ of the participants were nurses working in inpatient wards. Nearly half of the participants had more than 10 years of work experience and their type of employment been permanent (Table 1). 
Table 1. Demographic information of the participants

\begin{tabular}{llc}
\hline Variables & Categories & N $(\%)$ \\
\hline Gender & Male & $116(75.5)$ \\
Education level & Female & $33(24.4)$ \\
& Associate's degree & $45(29.2)$ \\
& Bachelor's degree & $90(58.4)$ \\
Age (years) & Master's degree or higher & $19(12.3)$ \\
& $<30$ & $36(23.40$ \\
& $30-40$ & $76(49.4)$ \\
Work experience (years) & $40-50$ & $35(22.7)$ \\
& $>50$ & $7(4.5)$ \\
& $<5$ & $49(31.8)$ \\
Job category & $5-10$ & $29(18.8)$ \\
& $10-15$ & $32(20.8)$ \\
& $>15$ & $44(28.6)$ \\
& Administrative & $37(24.0)$ \\
& Financial & $8(5.2)$ \\
& Medical & $12(7.8)$ \\
Employment type & Nursing & $67(43.5)$ \\
& Other & $30(19.5)$ \\
& Permanent & $69(44.80$ \\
& Contract & $71(46.1)$ \\
& Temporary & $14(9.1)$ \\
\hline
\end{tabular}

$\varepsilon \quad$ According to the questionnaire score ranking, the results of the study showed that the mean score of

- both HRS and OP were at intermediate level. However, among HSR, personnel training and

7 development, recruitment, and staff compensation and reward scored the highest. While among the

$\checkmark \quad$ various domains of OP, the domain of internal process received the highest score (Table 2).

$\wedge$

9 1.

Table 2. Descriptive statistics indicators of HRS and OP based on the responses of 154 participants in the study (total score and score of dimensions based on Likert scale)

\begin{tabular}{llcccl}
\hline Variable & Dimensions & N (Items) & Mean(SD) & Max(Min) & Level/rank \\
\hline HSR & Performance management & 4 & $3.31(0.45)$ & $4.13(2.40)$ & Medium Level \\
& Training and development & 8 & $3.32(0.43)$ & $4.22(2.49)$ & Medium Level \\
& Compensation & 4 & $3.45(0.44)$ & $4.13(2.67)$ & Medium Level \\
& Recruitment & 4 & $3.50(0.69)$ & $6.33(2.40)$ & Medium Level \\
& Equal opportunities & 4 & $3.07(0.55)$ & $3.84(1.95)$ & Medium Level \\
& Staff relations & 4 & $3.20(0.44)$ & $4.06(2.24)$ & Medium Level \\
& Flexible work programs & 4 & $3.98(0.69)$ & $4.00(2.60)$ & Medium Level \\
OP & Total score of HSR & 32 & $3.36(0.45)$ & $4.39(2.39)$ & Medium Level \\
& & & & & \\
& Customer & 8 & $3.26(0.64)$ & $4.67(2.00)$ & Medium Level \\
& Financial & 8 & $3.20(0.52)$ & $4.00(2.01)$ & Medium Level \\
& Internal process & 8 & $3.48(0.60)$ & $5.00(2.02)$ & Medium Level \\
& Learning and growth & 8 & $3.22(0.61)$ & $4.00(2.00)$ & Medium Level \\
& Total score of OP & 32 & $3.28(0.58)$ & $4.41(2.00)$ & Medium Level \\
\hline
\end{tabular}


1 Kolmogorov-Smirnov test showed that the main variables of the study (the scores of HRS and OP)

$r \quad$ had a normal distribution ( $\mathrm{p}>0.05)$.

$r \quad$ The results of Pearson correlation coefficient test showed that HRS had a positive correlation with all

$\varepsilon$ four dimensions of OP. The rate of correlation coefficient showed that OP in the dimension of - learning and growth had the highest correlation with HRS ( $\mathrm{r}=0.669)$, while OP in the dimension of $1 \quad$ internal process had the lowest correlation with HSR ( $r=0.359)$ (Table 3).

Table 3. Pearson correlation coefficient ( $\mathrm{r}$ ) between HRS and dimensions of OP

\begin{tabular}{|c|c|c|c|c|c|c|}
\hline Item & 1 & 2 & 3 & 4 & 5 & 6 \\
\hline 1. Customer & 1 & & & & & \\
\hline 2. Financial & 0.870 & 1 & & & & \\
\hline 3. Internal process & 0.925 & 0.870 & 1 & & & \\
\hline 4. Learning and growth & 0.913 & 0.832 & 0.895 & 1 & & \\
\hline 5. OP (total score) & 0.950 & 0.941 & 0.920 & 0.964 & 1 & \\
\hline 6. HSR (total score) & $0.455^{*}$ & $0.455^{*}$ & $0.359 * *$ & $0.669 *$ & $0.730 *$ & 1 \\
\hline
\end{tabular}

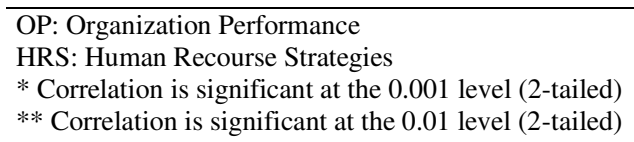

Multivariate regression analysis was used to simultaneously investigate the effect of seven type of HRS on OP. Before preparing the regression model and in order to confirm the validity of the regression model, first the multivariate regression hypotheses were examined and confirmed.

The results of regression analysis showed that all types of HRS were effective on OP (R=0.998, $\mathrm{R} 2=0.997, \mathrm{ADJ} . \mathrm{R} 2=0.997)$. Among these, staff training and development strategy $($ Beta $=0.265, \mathrm{p}=$ 0.000), personnel compensation and reward $($ Beta $=0.212, p=0.000)$ and recruitment strategy (Beta $=0.208, \mathrm{~B}, \mathrm{P}=0.000$ ) had the greatest impact on $\mathrm{OP}$ respectively. However, staff relations strategy $($ Beta $=0.156, p=0.000)$ had the lowest impact on OP $($ Table 4$)$. 


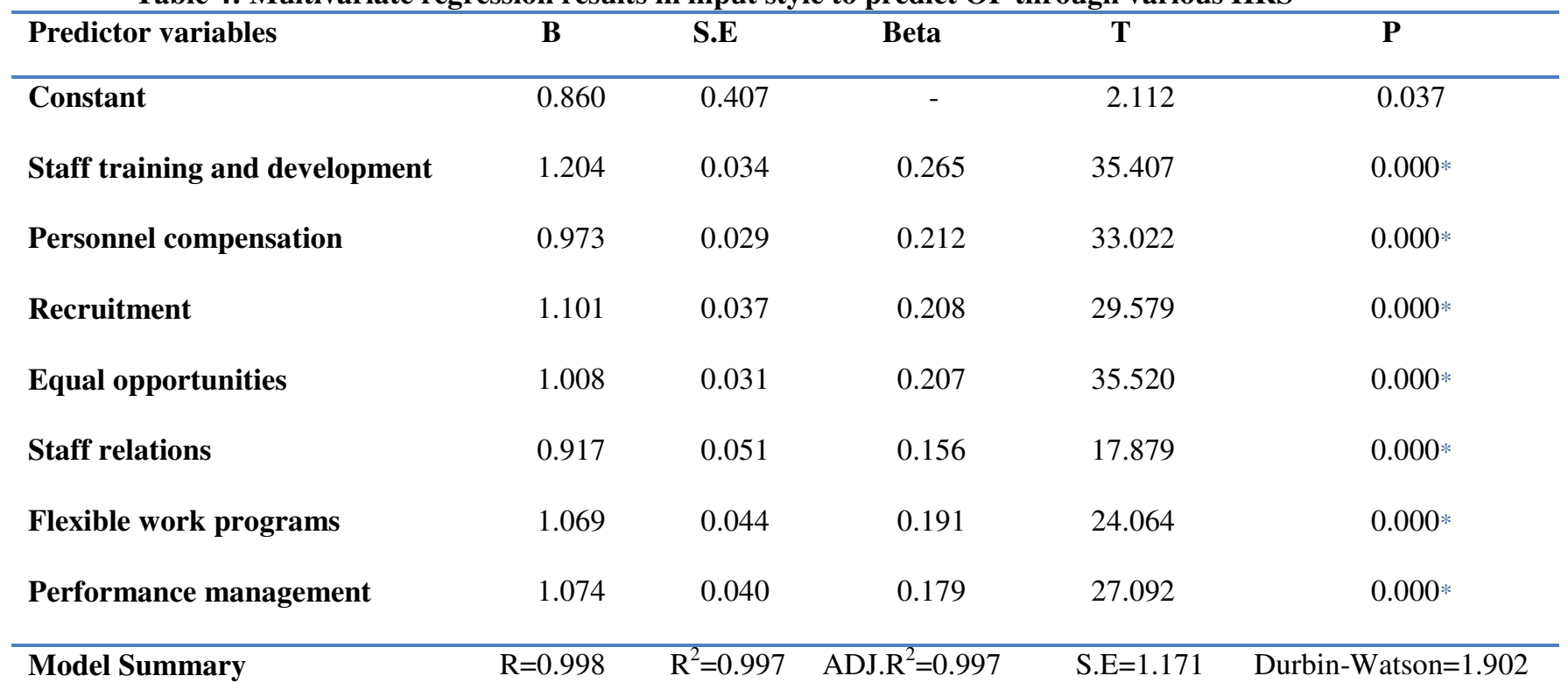

* Significant at the 0.001 level (2-tailed)

$\varepsilon$ Discussion:

- HRS is known as the common view of management and staff on the type of human resource policy

7 applicable in the organization. It is an important task of human resource management and should be

$\checkmark$ designed based on continuous dialogue with stakeholders and employees of the organization. A

$\wedge$ successful HRS determines what influences the success of an organization, what values the

9 organization respects, and what actions the organization takes when using and strengthening its

1. critical resources [4].

11 The present study showed that HRS was at intermediate level. This finding is consistent with the ir research by Ashourpour et al. (2015) in psychiatric hospitals in Tehran [18]. HRS is a joint ir development program of human resource and management that includes a long-term plan to determine I the policies, goals and actions of employees [4]. HRS indicates the capacity of the organization and a 10 mechanism to improve staff efficiency. These strategies are the basis of the organization's human 17 resource management and a prerequisite for the success of human resource management. Therefore, it iv seems necessary to improve staff perception of HRS through hospital human resource management 11 activities. 
On the other hand, the present study showed that the OP of the studied hospital was at the intermediate level. This finding is almost consistent with the research of Aghili and Tutunchi (2015) and the research of Jahanian et al. (2017) [10,24]. The vitality of hospital services and the complexity of health care require high organizational performance to ensure the quality and safety of health care. Although the OP reported in the present study is at an acceptable level, it seems that the safety and optimal quality of hospital services require high organizational performance.

In line of main purpose of the present study, liner regression analysis showed that all types of HRS were effective on OP. However, staff training and development strategy, personnel compensation and reward strategy and recruitment strategy were the strongest predictors of OP. The majority of national and international research point out that the successful implementation of HRS improves the performance of health care organizations [2,3,6,18-22].

In this regard, the studies by Ashourpour and Najafi (2015), and Ilyasi et al. (2015) which were conducted in public and university hospitals, showed that staff productivity and hospital performance can be improved through the development of HRS [18,19]. Nasiri et al. (2013) found that personnel training and development strategy, staff relations strategy, and performance management strategy have a significant correlation with OP [3]. In addition, Hamid and Mohammad (2016) in a study studied the relationship between human resource resources practices and OP in four private hospitals in southern India. They showed that staff recruitment strategy and staff training and development strategy are significant predictors of OP [20].

Another study in Jordanian public hospitals showed that there was a positive correlation between strategic human resource management factors (including manpower, training and development, motivation and maintenance) and OP. However, manpower and motivation factors had the greatest impact on the overall performance of hospitals [6].Most of these findings are consistent with the present study. It seems that hiring qualified medical staff and their training and career development has a significant positive effect on hospital performance. By applying appropriate human resource management practices in hospitals, individual productivity and organizational performance can be expected to be higher. 
The findings of the present study showed that the impact of HSR on OP in non-financial dimensions (including; growth and learning, customer, and internal process) is greater than the financial dimension. Some studies confirm this finding. In this regard, Vermeeren et al. (2016) by conducting a study in 162 Dutch health care institutions showed that human resources management activities and strategies have positive effect on financial (measure: net margin), organizational (measure: client satisfaction) and human resource outcomes (measure: sickness absence). But in the meantime, the impact of human resource activities on non-financial outcomes was much greater than the financial outcomes [2]. Valmohammadi and Ahmadi (2015) also found that knowledge management is only effective on OP in dimension of learning and growth [14]. These findings are consistent with the present study. It seems that HRS affects the performance of the organization in non-financial dimensions (staff and organization) more than financial performance. The financial performance of the organization is likely to be more dependent on financial management activities. But do not forget that improving the non-financial performance can indirectly improve the financial performance of the organization. Of course, this finding requires future studies in this field.

While most related studies have investigated the impact of HRS on overall hospital performance, Michael et al. (2006) examined the impact of policies and practices of human resource management on standardized patient mortality rates in 52 UK hospitals. They found these policies and practices have a significant and real effect on reducing patient mortality [21].In this regard, Elkomy and Cookson (2020) also showed that performance management strategies, especially the policy of reducing patient waiting time, had a positive effect on the health care outcomes reported by patients in UK acute hospitals [26].

Human resource is a key factor in gaining an organization's competitive advantage. Therefore, to achieve the desired OP, it is necessary to effectively manage human resources through appropriate strategies, in such a way that these strategies are consistent with the strategy of the organization [22]. When human resource system focuses on strategic decisions instead of emphasizing individual actions, it will have a significant impact on OP [25]. Since the attitude of health workers is an important element in the relationship between human resource management activities and the 
1 performance of health care institutions [2], the development of research in this area can provide useful

$r \quad$ information to improve the performance of these institutions.

$r \quad$ Limitations of the study: Research in one institution, type of the study (descriptive \& cross

$\varepsilon \quad$ sectional), small statistical population, low participation of physicians in the study, and self-report - method in completing the questionnaire are the limitations of this study, which can affect the 1 generalizability of the findings.

\section{$\checkmark$ Conclusion:}

$\wedge \quad$ The present study showed that there was a positive and significant relationship between HRS and OP.

9 In addition, HRS had the most relationship with OP in the dimension of growth and learning and the 1. least relationship in the dimension of finance. Regression analysis also showed that training and development strategy, staff compensation strategy and recruitment strategy had the strongest relationship with OP. In order to improve hospital performance, it seems that the development and implementation of HRS (especially training and development, compensation and recruitment) can be considered by hospital managers. It seems that HRS affects the performance of the organization in non-financial dimensions (staff and organization) more than financial performance. The financial performance of the organization is likely to be more dependent on financial management activities. But improving the non-financial performance can indirectly improve the financial performance of the organization. Of course, this finding requires future studies in this field.

Future studies are needed to confirm the findings of this study. It is suggested that future studies be conducted in a larger statistical community in private and public hospitals. Although this is a smallscale study, the results may be used to similar hospitals in similar context. Our study contributes to the development of research in this field.

Abbreviations: HRS: Human Research Strategies; OP: Organizational Performance 


\section{Acknowledgements:}

Much appreciation goes to the Research Deputy of Shahrekord Branch, Islamic Azad University who provided general support for this study. We would appreciate the personnel who helped us greatly in filling and returning the instruments.

\section{Authors' contributions:}

BR designed the study, carried out statistical analyses of the data, was involved in the interpretation of the data and wrote the manuscript; EN collected the data, was involved in the interpretation of the data and contributed to the manuscript. All authors read and approved the final manuscript.

Funding: Not applicable.

Availability of data and materials: The datasets used in the present study are accessible from the corresponding author on reasonable request.

\section{Ethics approval and consent to participate:}

This study was approved by the ethical committee of Shahrekord Branch, Islamic Azad University (N: IR .iau.shk.rec.1398.008). Written permission was obtained from the hospital management before beginning of the study. In this study, the subjects were obligation-free, and after signing the written informed consent form to participate in the study, they peacefully responded to unnamed questionnaire. In order to provide the privacy of the subjects, the study was strictly anonymous.

Consent for publication: Not applicable.

Competing interests: The authors declare that they have no competing interests.

\section{Author details:}

1. Department of Health \& Health Services Management, Medical Faculty, Shahrekord Branch, Islamic Azad University, Shahrekord, Iran. 2. Associate Professor, Nursing \& Midwifery Faculty, Falavarjan Branch, Islamic Azad University, Isfahan, Iran.

2. 


\section{References:}

1. Armstrong M. Strategic human resource management: A Guide to Action. Fourth edition 2008. Available from:

\section{http://103.5.132.213:8080/jspui/bitstream/123456789/1074/1/Armstrong_SHRM_Action.pdf}

2. Vermeeren et al.: HRM and its effect on employee, organizational and financial outcomes in health care organizations. Human Resources for Health, 2014, 12:35. Available from: http://www.human-resources-health.com/content/12/1/35

3. Nasiri M, Heidari M, Shahbazi S, Ansari E. Correlation of human resource strategies based on Allen Ylsy Model with organizational performance staff in Aiat Allah Kashani Hospital. Journal of Health Promotion Management. 2013; 2(3):36-44. Available from: http://jhpm.ir/article-1-125-en.html

4. Räsänen E. Human resource strategy: Work well-being as a strategic choice.Degree Programme in Entrepreneurship and Business Competence, Oulu University of Applied Sciences, spring 2021. Available from:

https://www.theseus.fi/bitstream/handle/10024/500978/Thesis\%20report\%20opinn\%C3\%A4ytety \%C3\%B6\%20Eeva\%20R\%C3\%A4s\%C3\%A4nen.pdf?sequence=2\&isAllowed=y

5. Bamberger PA, Biron M, Meshoulam I. Human resource strategy: Formulation, implementation, and impact. Second Edition, Routledge; 2014 Jun 27. https://doi.org/10.4324/9780203075838

6. Samara RA. Exploring the Link Between Strategic Human Resource Management System and Performance in Jordanian public hospitals (Doctoral dissertation),Middle East University), 2014. Available from:

https://www.meu.edu.jo/libraryTheses/58734eb21f28e_1.pdf

7. Armstrong M. A handbook of human resource management practice. Kogan Page Publishers; 2006. 10 th Edition. Available from:

http://103.5.132.213:8080/jspui/bitstream/123456789/308/1/Handbook\%20of\%20Human\%20Res ource.Management.Practice.pdf 
8. Becker B, Gerhart B. The impact of human resource management on organizational performance: Progress and prospects. Academy of management journal. 1996; 39(4):779-801. Available from: http://www.jstor.org/stable/256712

9. Ghasemi M. Investigating Human Resources Strategies with Organizational Performance in Firoozkooh Health Network. (Master's Thesis) Islamic Azad University, Firooz Kooh Branch.2013.

10. Aghili Mehrizi MR, Tutunchi J. Evaluating the Performance of Yazd Workers' Martyrs Hospital Using Balanced Scorecard Method, International Conference on Management, Economics and Industrial Engineering, Tehran. 2015. Available from:

\section{https://www.civilica.com/Paper-ICMEI01-ICMEI01_288.html}

11. Ghalavandi $\mathrm{H}$. The relationship between organizational change based on managerial factors and organizational performance. Applied Sociology, 2016; 27 (2): 141-156. doi: 10.22108 / jas.2016.20496

12. Kaplan RS, Robert NP, Kaplan RS, Norton DP. The strategy-focused organization: How balanced scorecard companies thrive in the new business environment. Harvard Business $\begin{array}{lll}\text { Press; } & 2001 . & \text { Available }\end{array}$ https://www.researchgate.net/file.PostFileLoader.html?id=5908d0d396b7e4808f21dbde\&asse $\underline{\mathrm{tKey}}=\mathrm{AS} \% 3 \mathrm{~A} 489637023096832 \% 401493749971366$

13. Kaplan RS, Norton DP. Using the balanced scorecard as a strategic management system. Harvard Business Review 1996; 74(1), 75-85. Available from: http://jackson.com.np/home/documents/MBA4/Management_accounting/BSCHarvardBusinessRe view.pdf

14. Valmohammadi C, Ahmadi M. The impact of knowledge management practices on organizational performance: A balanced scorecard approach. Journal of Enterprise Information Management 2015; 28 (1): 131-159. http://dx.doi.org/10.1108/JEIM-09-2013$\underline{0066}$ 
15. Pham CD, VU ST, PHAM YT, VU NT. Evaluating performance of Vietnamese public hospitals based on balanced scorecard. The Journal of Asian Finance, Economics, and Business. 2020;7(6):339-49. doi:10.13106/jafeb.2020.vol7.no6.339

16. Knies E, Boselie P, Gould-Williams J, Vandenabeele W. Strategic human resource management and public sector performance: context matters. The International Journal of Human Resource Management 2018, 1-13. https://doi.org/10.1080/09585192.2017.1407088

17. Gaturu P, Waiganjo E, Bichang'a W, Oigo D. Influence of Strategic Control on Organizational Performance of Mission Hospitals in Kenya. International Journal of Innovative Research \& Development. 2017;6(6):163-7.

https://doi: 10.24940/ijird/2017/v6/i6/JUN17088

18. Ashourpour S, Najafi A. Relationship between Human Resource Development Strategies and Staff Productivity in Psychiatric Hospitals Affiliated to Iran University of Medical Sciences. Hakim Health Sys Res 2015; 18(2): 153- 161. Available from:

http://hakim.hbi.ir/article-1-1515-fa.html

19. Eliassy Z, Mohammadvandipour M, Nouri A, Elyasi K. A Study of the Relationship between Strategic Human Resource Management and Organizational Performance at Ilam University of Medical Sciences. 3rd International Symposium on Management Sciences with a Focus on Sustainable Development, Tehran, 2016._Available from:

https://www.civilica.com/Paper-IMSYM03-IMSYM03_038.html

20. Hameed A, Mohamed NS. HRM practices and organizational performance in hospitals. ISOR Journal of Business Management. 2016; 18(11):34-41. DOI: 10.9790/487X-1811013441

21. Mitchell R, Obeidat S, Bray M. The effect of strategic human resource management on organizational performance: The mediating role of high-performance human resource practices. Human Resource Management. 2013; 52(6):899-921. https://doi.org/10.1002/hrm.21587 
22. Cania L. The impact of strategic human resource management on organizational performance. Economia. Seria Management. 2014; 17(2):373-83. Available from: http://www.management.ase.ro/reveconomia/2014-2/14.pdf

23. Chang WJ, Huang TC. Relationship between strategic human resource management and firm performance: A contingency perspective. International journal of manpower. $2005 \mathrm{Jul} 1$. https://doi/ 10.1108/01437720510615125

24. Jahanian A, Hamidian M, Khosravipour N, Azizi H. The gap between current and desired performance evaluation system of balanced scorecard in specialty and subspecialtyTehran's Milad hospital. Journal of Economic Studies, Financial Management and Accounting, 2017, 3(2): 102-113. Available from:

https://irijournals.ir/journals/02-Economics/v3-i2-summer96/paper7.pdf

25. Elkomy S, Cookson G. Performance Management Strategy: Waiting Time in the English National Health Services. Public Organization Review. 2020; 20(1):95-112. https://doi.org/10.1007/s11115-018-0425-7

26. Liu Y, Combs JG, Ketchen Jr DJ, Ireland RD. The value of human resource management for organizational performance. Business horizons. 2007; 50(6):503-11. . Available from: http://entofa.net/wp-content/uploads/2019/11/The-value-of-human-resource-management.pdf 